\title{
Med.Pix
}

\section{A netlike rash}

Raymond T Kuwahara

Stephen Carter

Division of Dermatology

University of Tennessee

Memphis, TN

Correspondence to:

Dr Kuwahara

750 Adams Ave, \#1109

Memphis, TN 38105

r.kuwahara@excite.com

Competing interests:

None declared

West J Med

2000;173:370-371

QUESTION: A 59-year-old man is seen because of a netlike rash in the sacral area. The rash began 2 months ago and was neither pruritic nor painful. The patient has a long history of arthritis and back pain. On physical examination, a hyperpigmented reticulated rash is seen on the sacral area (figure).

What additional history would help to make this diagnosis?

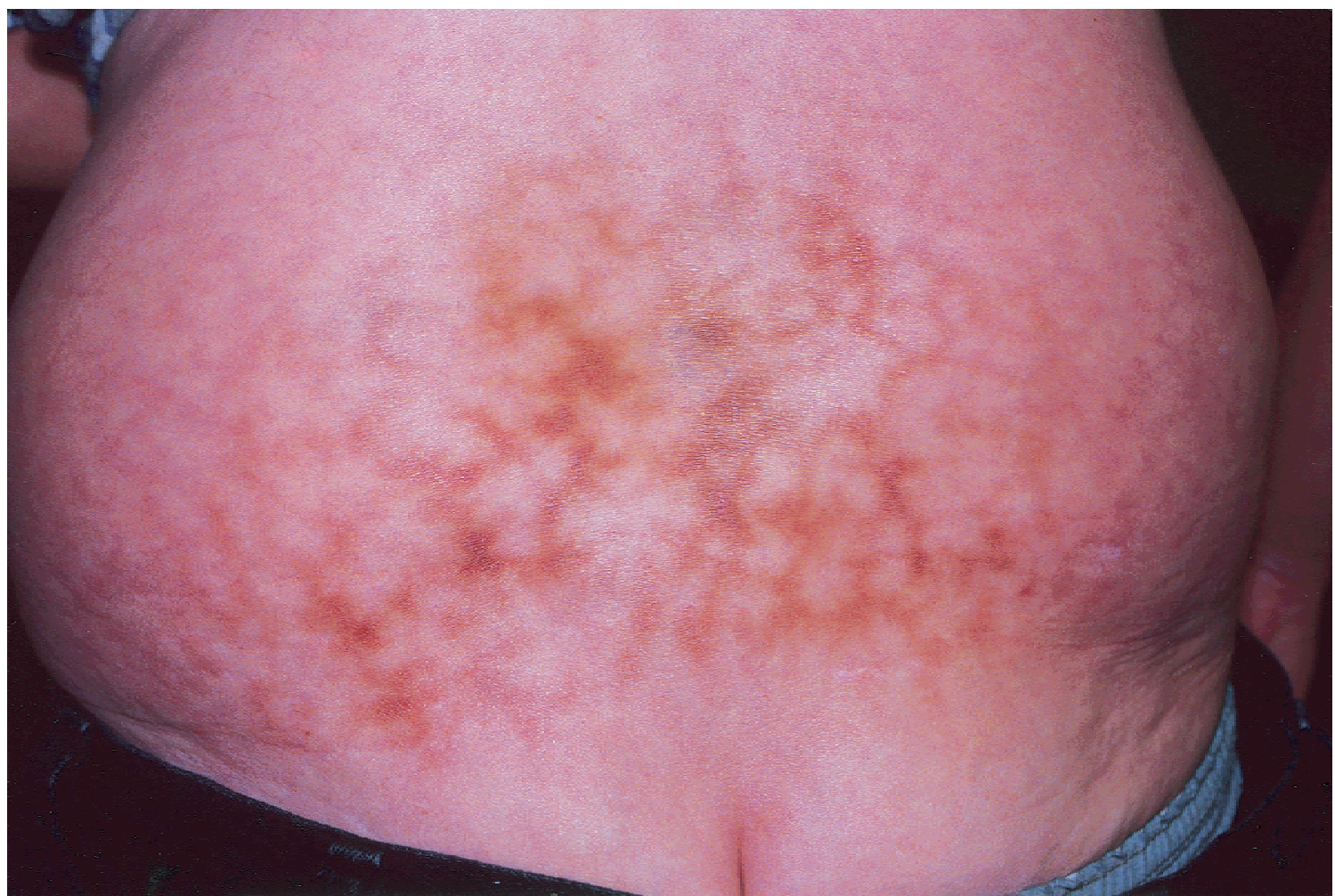

Netlike rash on sacral area

ANSWER: Additional history revealed that the patient started using a heating pad to soothe his back pain about the same time the reticulated rash began to appear.

The patient has erythema ab igne ("red from fire"), also known as toasted-skin syndrome, heat-induced circumscribed dermal melanosis, fire stains, ephelis ignealis, or livedo reticularis e calore.

Erythema ab igne is a cutaneous disorder caused by absorption of infrared radiation. Women are affected more often than men. ${ }^{1}$ Patients have a history of repeated exposures to heat at a lower level than that which causes a thermal burn. The skin is often mildly erythematous initially, but after repeated heat exposures, the classic blue, purple, or brown reticulated hyperpigmentation develops. ${ }^{1}$

Because of the general availability of central heating, erythema ab igne is less common in the United States than in countries where open fires are commonly used for heating. Historically, this condition was often seen on the inner thighs and legs of women who sat in front of a stove or open fire. ${ }^{1,2}$ Currently, it is most commonly seen in this country following repeated use of hot water bottles, infrared lamps, and heating pads. Erythema ab igne has been reported to appear on the legs following prolonged, daily exposure to a car heater. Occasionally, the first sign of splenomegaly, pancreatitis, pancreatic cancer, and other 
cancers is erythema ab igne resulting when patients apply external heat to relieve the underlying pain. ${ }^{2}$ Work exposure to heat (such as for bakers, silversmiths, and boiler operators) may cause this condition. ${ }^{1}$

\section{RISK OF MALIGNANT TRANSFORMATION}

A small risk of malignant transformation is thought to be present in the area affected by erythema ab igne. ${ }^{1,2}$ Carcinoma can develop from dysplastic keratinocytes that are harbored within the reticulated hyperpigmentation. Both squamous cell carcinoma and Merkel cell carcinoma have been known to arise within erythema ab igne. Patients should be evaluated regularly so that any thermal keratoses (similar to actinic keratoses) or other premalignant lesions can be treated appropriately.

\section{DIFFERENTIAL DIAGNOSIS AND TREATMENT}

An important disorder to consider in the differential diagnosis is livedo reticularis. Livedo reticularis is characterized by reddish blue mottling of the skin in a reticular pattern. It occurs more often in women. Livedo reticularis may be due to other disorders, including vasospastic conditions, connective tissue disorders, and drug reactions. Unless symptoms are present that are related to an underlying disorder, patients typically have no complaints other than the cosmetic appearance of the skin. In contrast to erythema $\mathrm{ab}$ igne, the skin manifestations of the benign form of livedo reticularis resolve with heating. In livedo reticularis that is secondary to another disorder, the underlying disease process should be treated. ${ }^{3}$

No definitive therapy for erythema ab igne is available. Reducing or eliminating exposure to the heat source early in the disorder may reverse the hyperpigmentation. ${ }^{1}$ However, prolonged exposure leads to permanent hyperpigmentation and increased risk of malignant transformation. Treatment with topical fluorouracil may be useful in reducing or eliminating dysplasia of keratinocytes.

This patient was instructed to turn down the heat setting on his heating pad and to use the pad less often. On follow-up 2 months later, the hyperpigmentation had decreased.

Authors: Raymond Kuwahara is Chief Resident, Division of Dermatology, and Stephen Carter is a 4th-year medical student, both at the University of Tennessee, Memphis.

References

1 Dvoretzky I, Silverman NR. Reticular erythema of the lower back. Arch Dermatol 1991;127:405-406, 408-409.

2 Meffert JL, Davis BM. Furniture-induced erythema ab igne. J Am Acad Dermatol 2000;34:516-517.

3 Freedberg IM, Eisen AZ, Wolff K, et al. Fitzpatrick's Dermatology in General Medicine. 5th ed. New York: McGraw-Hill; 1999.

\section{How to submit your medical images for publication in Med.Pix}

Do you have images (slides, photos, etc.) of compelling visual cases in clinical medicine?

If other primary care providers would find them interesting, we would like to publish them, along with a brief description of the clinical presentation and a question for the readers. The answer should provide an explanation of the clinical case along with information on differential diagnosis and treatment. The treatment section should suggest an evidence-based approach and be supported by current references. Multiple images may be submitted, and interesting connections between these images may be highlighted.

High-quality slides, illustrations, and photographic prints may be mailed to:

Richard Usatine, MD; Section Editor, Med.Pix; 200 UCLA Medical Plaza, Suite 220, Los Angeles, CA 90095-1628; Fax 310-206-0181.

Written descriptions and electronic images may be submitted to: rusatine@mednet.ucla.edu.

Note: If the patient's identity is recognizable, a signed permission form should accompany the submission materials. 